\title{
Transmedia literacy in professional training practices: A case study
}

\author{
Keywords \\ Transmedia literacy, Professional practices, Educational practices, Methodological proposal.
}

The changes the digital age brought in communicative practices produced under transmedia logic allow the structure of increasingly complex texts, produced by open, polyphonic, simultaneous, accelerated, and hybrid archenunciations, which expand into different genres, formats, languages, and media, determining new forms of production, reception, and circulation of content. New ethics and aesthetics shape cultural productions in all spheres, especially in the area of entertainment and the arts. Virtual reality, metaverses, among other modifications, demand new communicative skills and abilities - that is to say, a new literacy to the persons. In addition, the COVID-19 era inserted the processes and practices of professional training in the Internet's digital ecosystem, also demanding from its actors new interaction regimes with the educational practices that arise in this context. Digital platforms start to mediate the relationships of these actors with knowledge, configuring new ways of life for the learner. To identify the characteristics of the profile of these students and how they are relating to these emerging educational practices, we are developing a project entitled "Transmedia literacy in the era of education platform", whose objective is to identify and analyze the produced and circulated transmedia literacy by students enrolled in professional training courses and inserted in educational practices mediated by digital technologies. We understand Transmedia Literacy as a communicative competence carried out in the universe of cultural and media convergence of the digital age, and as a theoretical-methodological proposal for research, teaching, and learning of transmedia communicative practices of reading, interpreting, producing, and disseminating texts. This proposal is based on transdisciplinary relationships from cross-relationships between the assumptions of the area of Social Communication, Linguistics, and discursive Semiotics. It is part of a context of cultural and transmedia convergence to which subjects migrate their social practices in an ever-accelerating manner. Assuming that literacy problems directly impact the teaching and learning processes of students in professional training processes, we propose to carry out a comparative study between the literacy skills of students in educational practices mediated by the digital platforms of formal education and their literacy daily life produced in the digital spaces through which they transit. We aim to identify the interaction regimes, types, and degrees of literacy and, therefore, the relationship of students with the knowledge offered by institutions. With Castells (2007), we consider that there is a great cultural and technological gap between today's youth and a school system that did not evolve along with society and the digital environment. Thus, it is intended that the results of this research have a direct impact on formal educational practices, offering data and a methodological proposal that allows institutions and professors to adapt their practices to the profile of their students, improving their relationship with the processes and practices of teaching and learning, thus ensuring excellence in the processes and practices of professional training in the areas of Art and Design. 